\title{
Glucocorticoid Hormones Decrease Proliferation of Embryonic Neural Stem Cells through Ubiquitin-Mediated Degradation of Cyclin D1
}

\author{
Maria Sundberg, ${ }^{1}$ Suvi Savola, ${ }^{1}$ Anni Hienola, ${ }^{3}$ Laura Korhonen, ${ }^{1,2}$ and Dan Lindholm ${ }^{1,2}$ \\ ${ }^{1}$ Minerva Medical Research Institute, Biomedicum Helsinki, FIN-00290 Helsinki, Finland, ${ }^{2}$ Department of Neuroscience, Unit of Neurobiology, Uppsala \\ University, Biomedical Centre, S-751 23 Uppsala, Sweden, and ${ }^{3}$ Neuroscience Center, Department of Biosciences and Institute of Biotechnology, University \\ of Helsinki, 00014 Helsinki, Finland
}

\begin{abstract}
Corticosteroids can influence brain function, and glucocorticoid hormone receptors (GRs) are present in brain tissue. We observed that GR and also mineralocorticoid receptor (MR) are expressed by embryonic rat neural stem cells (NSCs). NSCs in developing ventricular epithelium were positive for GR. Stimulation of cultured NSCs with the specific receptor ligands dexamethasone and corticosterone reduced cell proliferation, shown by $5^{\prime}$-bromo-2-deoxy-uridine labeling. The effect of the hormones was dose dependent and inhibited by the GR blocker mifepristone but not by spironolactone, blocking MR. Dexamethasone inhibited the cell cycle by decreasing the levels of cyclin D1 in NSCs. The hormone-induced decline was inhibited by MG132 (benzyloxycarbonyl-leucyl-leucyl-leucinal), showing an involvement of the ubiquitin proteasome system, In keeping with this, dexamethasone increased the ubiquitination of cyclin D1. In embryonic brain, dexamethasone inhibited cell proliferation of NSCs. This demonstrates that embryonic NSCs are critically influenced by glucocorticoids, which can have long-term effects in the brain.
\end{abstract}

Key words: neural stem cells; glucocorticoids; hormone receptor; cyclin D; cell proliferation; proteasome

\section{Introduction}

Corticosteroid hormones are divided into glucocorticoids and mineralocorticoids, which both are secreted by the adrenal cortex. The levels of corticosteroids are regulated by feedback mechanisms involving the hypothalamic-pituitary-adrenal (HPA) axis. Stressful environmental changes activate the HPA axis elevating the corticosteroids (de Kloet et al., 1998, 2005). Cortisol is the physiological glucocorticoid in man, whereas in rodents this is corticosterone (Cort). Glucocorticoids act via receptors (GRs) and influence cell metabolism and the inflammatory response. Aldosterone in turn acts via the mineralocorticoid receptor (MR) and controls the transport of natrium across membranes. GR and $\mathrm{MR}$ are ligand-specific transcription factors that are bound to heat shock proteins in their inactive state and translocate to the nucleus after ligand binding. Specific glucocorticoid-responsive elements are present in target genes and mediate effects on gene transcription (Beato, 1989).

In the brain, GRs are present in different brain regions in both neurons and glial cells (Fuxe et al., 1985; Van Eekelen et al., 1991; Schmidt et al., 2003). The expression of MR is more restricted

Received Nov. 16, 2005; revised March 30, 2006; accepted April 2, 2006.

This work was supported by the Medical Research Council, Minerva Foundation, Signe and Ane Gyllenberg Foundation, Liv och Hälsa, and Arvo and Lea Ylppö Foundation. We thank Mirkka Turunen for help with animals, Tuulikki Nyman for PCR, and Eeva Lehto and Johanna Mäkelä for skillful technical assistance.

Correspondence should be addressed to Dan Lindholm, Department of Neuroscience, Biomedical Center, Box 587, S-75123 Uppsala, Sweden. E-mail: dan.lindholm@neuro.uu.se.

D0I:10.1523/JNEUROSCI.4906-05.2006

Copyright $\odot 2006$ Society for Neuroscience $\quad$ 0270-6474/06/265402-09\$15.00/0 and mainly confined to hippocampus in the adult brain. Activation of GR has effects on various processes that alter behavior, memory, mood, and the survival of specific neurons (de Kloet et al., 1998; Crochemore et al., 2005). Glucocorticoids are known to influence developmental processes (Gass et al., 2001; de Kloet et al., 2005), and early exposure to stress has persistent effects on learning abilities and behavior (Lemaire et al., 2000). The molecular and cellular basis of these effects is not fully understood.

Neural stem cells (NSCs) are present in developing neuroepithelium but also in the fully mature nervous system in certain neurogenic regions, such as in the dentate gyrus and the lining of the lateral ventricles (Taupin and Gage, 2002). Previous studies have shown that neurogenesis in the adult hippocampus is sensitive to various factors, such as growth hormones (Åberg et al., 2000; Gould and Gross, 2002; Schanzer et al., 2004), learning (Gould et al., 1998), and various drugs (Lemaire et al., 2000). In addition, the hormonal milieu plays an important role for adult brain neurogenesis, as shown for the sex steroids estrogens (Tanapat et al., 1999; Perfilieva et al., 2001; Brännvall et al., 2002; Tanapat et al., 2005) and androgens (Perfilieva et al., 2001; Brännvall et al., 2005). In adults, administration of glucocorticoid hormones negatively influence neurogenesis (Cameron and Gould, 1994; Gould et al., 1998; Karishma and Herbert, 2002).

However, the effects of glucocorticoids in embryonic NSCs and developing brain are essentially unknown. We show here that NSC isolated from embryonic brain express GR and MR. Dexamethasone (Dex) dramatically inhibited proliferation of embryonic NSCs, which was accompanied by a decrease in cyclin D1. The mechanism 
involved the proteasome-mediated degradation of cyclin D1 regulating the cell cycle. In vivo, dexamethasone reduced the proliferation of NSCs in embryonic brain, showing an important effect of the hormone on brain development.

\section{Materials and Methods}

Animals. Wistar rats were obtained from Harlan (Horst, The Netherlands) and housed at $12 \mathrm{~h}$ light/dark cycle with food available ad libitum. All experiments were approved by the local ethical committee and performed in accordance with the European Communities Council Directive $(86 / 609 / \mathrm{EEC})$.

Preparation and dissociation of NSCs. Striatum was dissected from embryonic day 17 (E17), and NSCs were prepared as described previously (Brännvall et al., 2002, 2005; Korhonen et al., 2003). Cells were incubated at $+37^{\circ} \mathrm{C}$ in 5\% $\mathrm{CO}_{2}$ atmosphere in Corning (Helsinki, Finland) Suspension Culture dishes $\left(5 \times 10^{6}\right.$ cells per $10 \mathrm{~cm}$ dish; Corning) or in Corning Ultra Low Attachment dishes (Corning) in NSC medium containing $15 \mathrm{~nm} \mathrm{HEPES,} \mathrm{pH}$ 7.5, $2.5 \mathrm{~mm}$ L-glutamine, $100 \mathrm{U} / \mathrm{ml}$ penicillin, $100 \mu \mathrm{g} / \mathrm{ml}$ streptomycin, 20 $\mathrm{ng} / \mathrm{ml}$ epidermal growth factor (EGF) (PeproTech, Rocky Hill, NJ), and B27 supplement (Invitrogen, Espoo, Finland) in DMEM/F-12 (Invitrogen). Neurospheres were grown for $4-5 \mathrm{~d}$, gently dissociated, and collected by centrifugation for $5 \mathrm{~min}$ at $1500 \mathrm{rpm}$. The cells were resuspended into appropriate volume of medium containing EGF, hormones, and inhibitors as indicated.

NSC viability and proliferation assay. NSCs were cultured in 96-well cell culture dishes (70,000 cells per well; Costar 3599; Corning) in $100 \mu \mathrm{l}$ of serum-free medium in the presence of $20 \mathrm{ng} / \mathrm{ml} \mathrm{EGF}$ and different concentrations of Dex and Cort (both from Sigma, Helsinki, Finland) as indicated in the figures. Mifepristone [RU-486 (17 $\beta$-hydroxy-11 $\beta$-(4-methylaminophenyl)-17 $\alpha$-(1-propynyl) estra-4,9-dien-3 one-6-7)] and spironolactone [7 $\alpha$-(acetylthio)-17 $\alpha$-hydroxy-3oxopregn-4-ene-21carboxylic acid lactone] (both from Sigma) were used to inhibit GR and MR, respectively. To estimate the viability of cells, we used the MTT [3-(4,5-dimethylthiazol-2yl)-2,5-diphenyltetrazolium bromide (Sigma)] assay as described previously (Brännvall et al., 2002, 2005).

For 5'-bromo-2-deoxy-uridine (BrdU) labeling, NSCs were incubated in $35 \mathrm{~mm}$ dishes $\left(10^{6}\right.$ cells per dish, Corning Ultra Low Attachment) in culture medium in the presence of $1 \mu \mathrm{M}$ Dex or $1 \mu \mathrm{M}$ Cort. After $2 \mathrm{~d}$, $\operatorname{BrdU}(10 \mu \mathrm{m}$; Sigma) was added, and the incubation was performed for an additional $24 \mathrm{~h}$, after which cells were dissociated and plated onto 50 $\mu \mathrm{g} / \mathrm{ml}$ poly-DL-ornithine (Sigma)-coated coverslips (150,000 cells per well; Costar 3524; Corning). After attachment, NSCs were fixed for 20 min with $4 \%$ paraformaldehyde, washed three times with PBS, $\mathrm{pH} 7.4$, and treated with $2 \mathrm{M} \mathrm{HCl}$ for $30 \mathrm{~min}$ at room temperature. Cells were washed twice with PBS, blocked for $1 \mathrm{~h}$ in 3\% BSA (Sigma), 0.1\% Triton $\mathrm{X}-100 / \mathrm{PBS}$, and primary rat anti-BrdU (diluted 1:200; Sigma). The next day, cells were washed three times with PBS and incubated for $2 \mathrm{~h}$ with the secondary anti-rat cyanine 3 (Cy3) antibody (diluted 1:200; Jackson ImmunoResearch, Cambridgeshire, UK). Cells were washed three times with PBS and counterstained using Hoescht $(4 \mu \mathrm{g} / \mathrm{ml}$; Sigma) before mounting in Gel Mount. The number of total and BrdU-positive cells were counted using microscopy in four nonoverlapping fields per coverslip. Experiments were repeated more than three times, and ANOVA was used for statistical analysis.

To transfect NSCs, we used the Amaxa (Cologne, Germany) Nucleofector kit and equipment and $8 \mu \mathrm{g}$ of pDEST26 expression vector encoding human cyclin D1. Transfection with enhanced green fluorescent protein (GFP) was used as control. At $24 \mathrm{~h}$ after transfection, half of the cells were treated for $2 \mathrm{~d}$ with Dex, and cell proliferation was analyzed by BrdU labeling.

Cell differentiation. NSC were plated onto $50 \mu \mathrm{g} / \mathrm{ml}$ poly-DL-ornithinecoated 24-well culture dishes (150,000 cells per well; Costar 3524; Corning) and incubated for $5 \mathrm{~d}$ in the presence of Dex (Brännvall et al., 2002; Korhonen et al., 2003). The cells were fixed for $20 \mathrm{~min}$ using $4 \%$ paraformaldehyde, blocked in $1 \%$ BSA and $0.1 \%$ Triton X-100, washed by PBS, incubated for 30 min with $0.3 \% \mathrm{H}_{2} \mathrm{O}_{2}$ to inhibit endogenous peroxidases, and blocked for $1 \mathrm{~h}$ using 3\% BSA in PBS/0.1\% Triton X-100. The following primary antibodies were used and added overnight at $4{ }^{\circ} \mathrm{C}$ : monoclonal mouse anti$\beta$-tubulin (diluted 1:200; BioSite, Helsinki, Finland), rabbit anti-glial fibril- lary acidic protein (1:200; Sigma), and rabbit anti- $\alpha$-nestin (1:1000; Chemicon, Helsinki, Finland). Secondary Cy2 anti-mouse and Cy2 anti-rabbit antibodies (1:200; Jackson ImmunoResearch) were added for $1 \mathrm{~h}$ in PBS in $1 \%$ BSA and $0.1 \%$ Triton X-100. The number of immunoreactive cells in each well was counted using fluorescent microscopy in four independent fields. Statistical analysis was done as above.

Western blotting and immunohistochemistry. This was done essentially as described previously (Korhonen et al., 2001; Brännvall et al., 2002, 2005). NSCs were incubated as above, and cells were lysed in radioimmunoprecipitation assay (RIPA) buffer containing $1 \%$ SDS and $10 \mathrm{~mm}$ Tris- $\mathrm{HCl}$, pH 7.4 to detect GR or using $50 \mathrm{~mm}$ Tris-HCl, pH 7.4, $150 \mathrm{~mm} \mathrm{NaCl,} \%$ NP-40, $0.25 \%$ Na-deoxycholate, $1 \mathrm{~mm}$ EDTA, and a protease inhibitor cocktail (Roche, Espoo, Finland) to detect cell cycle proteins. In some experiments, MG123 (Calbiochem, Espoo, Finland) was used to inhibit the activity of the proteasome (Yu et al., 2003). Protein concentrations were determined by Pierce (Helsinki, Finland) protein assay, and equal amounts of proteins were loaded onto a $10 \%$ SDS-gel for separation. Loading was further controlled by PonceauS staining (Sigma). The gel was transferred onto a nitrocellulose membrane (Amersham Biosciences, Helsinki, Finland) and incubated with primary antibodies such as rabbit anti-GR antibody (1:250; Affinity BioReagents, Helsinki, Finland), mouse anti-MR antibody (1:100; Affinity BioReagents), mouse anti-cyclin D1 (1:700; Santa Cruz Biotechnology, Helsinki, Finland), mouse anti-p18 (1:400; BD Biosciences, Helsinki, Finland), mouse anti-p27 (1:800; BD Biosciences), mouse monoclonal anti-ubiquitin antibody, P4G7 (1:1000; BioSite), or rabbit anti-actin (1:1000; Sigma). After washing, the filter was incubated with horseradish peroxidase-conjugated secondary anti-rabbit/mouse antibodies (1:2500; Pierce) and detected using the ECL method. Actin was used as control. In some experiments, $100 \mu \mathrm{g}$ of ubiquitin ladder (Affiniti Research, Exeter, UK) was analyzed to show the size of the ubiquitinated protein.

To detect GR and MR in embryonic rat brain, specimens were embedded in paraffin, sectioned using a microtome, and collected onto Superfrost slides. Sections were deparaffinated, and antigen retrieval was performed by boiling for $5 \mathrm{~min}$ twice in $0.01 \mathrm{M}$ citric acid, $\mathrm{pH}$ 6.0. Sections were fixed for $1 \mathrm{~h}$ in $5 \%$ BSA and $0.1 \%$ Triton X-100/PBS and processed for staining and visualization as described above, using anti-GR and anti-nestin antibodies (1:1400; Chemicon) for double staining.

Immunoprecipitation and ubiquitination of cyclin D1. For immunoprecipitation cells were lysed in RIPA buffer (see above) supplemented with protease inhibitor cocktail (Roche). The lysates were precleared with protein $\mathrm{G}$-agarose (Roche) for $1 \mathrm{~h}$, followed by determination of protein and an overnight incubation with primary mouse anti-cyclin D1 antibody (Santa Cruz Biotechnology). A total of $40 \mu$ l of protein G-agarose (Roche) was added to each lysate for $2 \mathrm{~h}$, followed by three washes with lysis buffer. Agarose beads were boiled, and proteins were separated as described above. The anti-ubiquitin antibody P4G7 (1:300; BioSite) was used to detect ubiquitinated cyclin D1.

PCR analysis. The presence of transcripts for cyclin D1, GR, and MR in NSCs was determined by reverse transcriptase (RT)-PCR. Total RNA was extracted using GenElute Mammalian Total RNA Miniprep kit (Sigma) from cells according to the instructions of the manufacturer. A total of $1 \mu \mathrm{g}$ of RNA was used for cDNA synthesis using $200 \mathrm{U}$ of Moloney murine leukemia virus RT (Invitrogen) with $12.5 \mu \mathrm{g} / \mathrm{ml}$ oligo- dT primer (Promega, Helsinki, Finland) and appropriate ingredients and buffer (Invitrogen). PCR was performed using the conditions of $94^{\circ} \mathrm{C}$ for $1 \mathrm{~min}, 55^{\circ} \mathrm{C}$ for $1 \mathrm{~min}$, and $72^{\circ} \mathrm{C}$ for $1 \mathrm{~min}$ for 30 cycles with a $10 \mathrm{~min} 72^{\circ} \mathrm{C}$ final extension. The specific oligonucleotides (Thermo Electron Corporation, Bremen, Germany) were as follows: GR, 5'-GTCCATGGGGCTGTATATGG-3' (upstream) and 5' TCCTCATTCGTGTTCCCTTC-3' (downstream) corresponding to nucleotides 59-78 and 518-537 in the rat sequence; MR, 5'-TCAGACCTTGGAGCGTTCTT-3' (upstream) and '5'-AGTGTGGAGGACCTGTGACC-3' (downstream) corresponding to nucleotides 56-75 and 430-449. For cyclin D1, the oligonucleotides were as follows: 5'-AAGTAGTGGCATCCGC-3' (upstream) and 5'-CCCGTCTCCCTATACTCAG-3' (downstream) corresponding to nucleotides 1041-1057 and 1253-1272 in the rat sequence; $\beta$-actin, $5^{\prime}$-TGTTTGAGACCTTCAA-3' (upstream) and 5' - TTGGCGTACAGGTCTTTGCGG-3' (downstream). 
In vivo experiments. Dex was injected intraperitoneally $(100 \mu \mathrm{g} / \mathrm{kg})$ to timed-pregnant E14 rats for $3 \mathrm{~d}$, and the controls received saline. BrdU $(100 \mathrm{mg} / \mathrm{kg}$, dissolved in $0.9 \%$ saline) was given for the last $2 \mathrm{~d}$. Rats were anesthetized and decapitated, and the brains of the pups were immediately removed, rinsed with PBS, and fixed for $24 \mathrm{~h}$ in $10 \%$ Formalin. Brains were stored up to $3 \mathrm{~d}$ in $70 \%$ ethanol and then dehydrated in an alcohol series and embedded in paraffin. Sections at $15 \mu \mathrm{m}$ were cut using a Leitz (Wetzlar, Germany) microtome and placed on SuperFrost Plus glass slides (Menzel-Gläser, Espoo, Finland).

Sections were deparaffinized with xylene and incubated in ethanol and water. Antigen retrieval was done as above, and the sections were treated for $30 \mathrm{~min}$ at $67^{\circ} \mathrm{C}$ with $1 \mathrm{M} \mathrm{HCl}$ and washed with PBS. Primary mouse antinestin and rat anti-BrdU antibodies were added overnight at $4^{\circ} \mathrm{C}$, followed by washing of sections with PBS. The additional incubation was at room temperature for $1 \mathrm{~h}$ using secondary AlexaFluor 488 anti-rat $(1: 2000)$ and AlexaFluor 568 anti-mouse (1:2000; Invitrogen, Carlsbad, CA) antibodies. Sections were washed and mounted with gel mounting medium (Gel Mount; Sigma).

Stereology. The number of BrdU-nestin double-positive cells in the developing rat brain was determined using unbiased stereology methods and the Stereo Investigator (MicroBrightField, Magdeburg, Germany) platform attached to an Olympus Optical (Tokyo, Japan) BX51 microscope. Cells were counted using the optical fractionator method in combination with the dissector principle and unbiased counting rules (Mouton et al., 2002; Hienola et al., 2004). The method was optimized to give a coefficient of error $<8 \%$ per individual brain sample. Three individual brains from Dex-treated and control animals were analyzed. Every 10th section was selected in a systematic random manner from a total number of 52-60 sections through the hippocampus of each brain, which generated five sections per reference space per brain. Each reference space was outlined at low power $(10 \times)$, and cells were counted using a highmagnification $(63 \times, 1.4$ numerical aperture oil-immersion) objective. Cell number in the ventricular zone of ganglion eminence was counted from the same section. The reference volume was estimated using Cavaleri dot grid $(75 \times 75 \mu \mathrm{m})$ to give the density in the ventricular zone. Statistical analyzes was done using Student's $t$ test.

\section{Results}

GRs are expressed in embryonic NSCs

and in developing rat neuroepithelium

NSCs were prepared from embryonic rat brain and cultured as neurospheres in the presence of EGF. The expression of the receptors for corticosteroid hormones was studied using RT-PCR. Figure $1 \mathrm{~A}$ shows the presence of transcripts for GR in embryonic and adult NSCs. In contrast, the level of MR was higher in embryonic compared with adult NSCs (Fig. 1A). Western blot analyses using specific antibodies for the receptors showed that

B
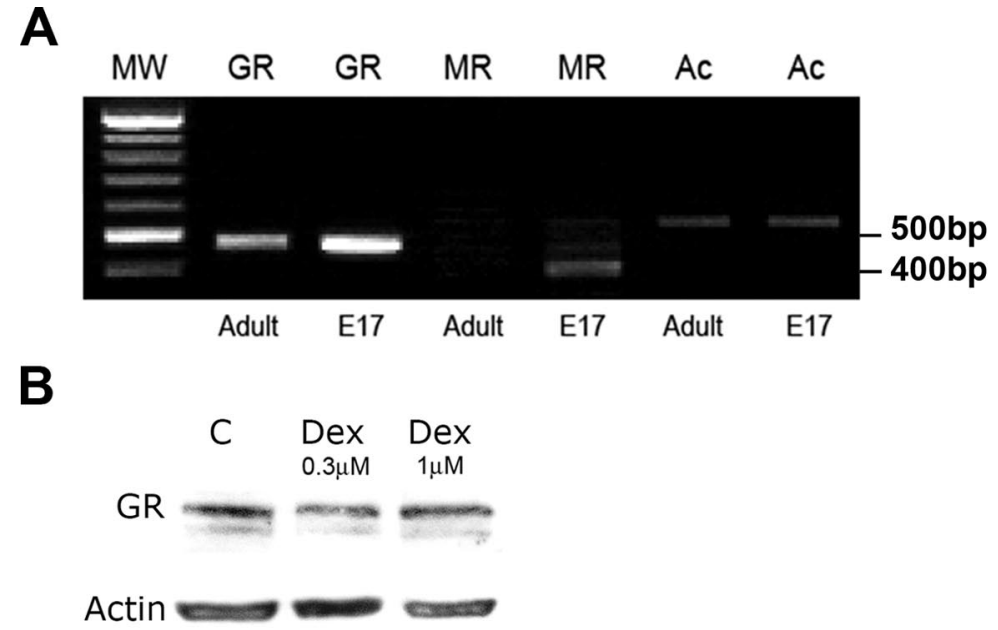

C Cort
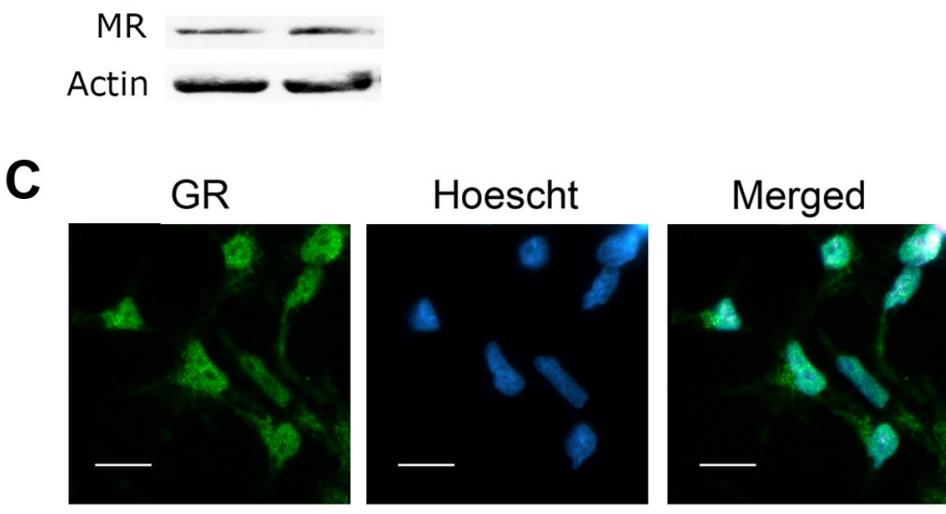

\section{D $\quad$ GR}
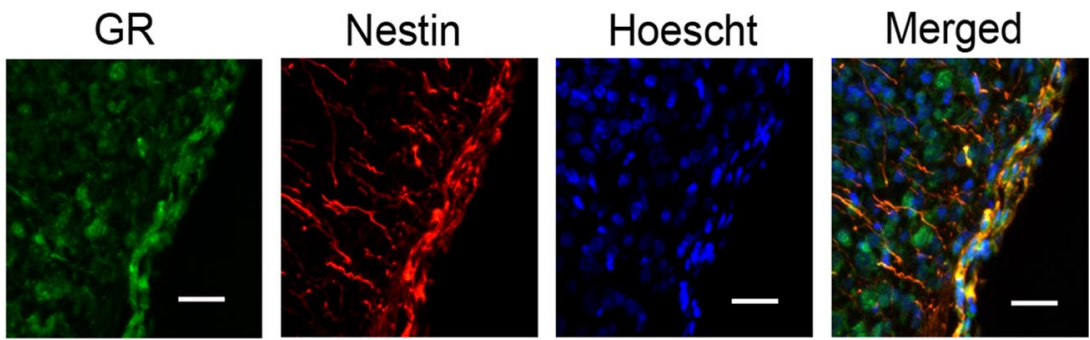

Figure 1. Expression of glucocorticoid and mineralocorticoid receptors in NSCS. A, NSCs were prepared from striatum of embryonic E17 and adult rat brain, and RT-PCR for GR and MR was made as described in Materials and Methods. GR (478 bp) was expressed in embryonic and adult NSCs, but MR (393 bp) was only detected in embryonic cells. $\beta$-Actin (Ac) was used as control. $\boldsymbol{B}$, Lysates from embryonic NSCs were subjected to Western blotting as described in Materials and Methods. Note the presence of GR $(97 \mathrm{kDa})$ and MR (116 kDa) in control (C) and hormone-treated cells. $\beta$-Actin was used as control. C, NSCs from E17 rat brain were cultured as neurospheres as described in Materials and Methods. Cells were fixed and immunostained with antibodies against GR (green color) and analyzed using fluorescent microscope. Nuclei are stained with Hoescht blue. Scale bars, $15 \mu \mathrm{m}$. Control without primary antibody showed no staining. D, Developing neuroepithelium contains GR-positive NSCs. Sections from E17 rats were cut on a cryostat, fixed, and incubated with antibodies against GR (green) and nestin (red) as described in Materials and Methods. Note the expression of GR in the lateral ventricular wall. Nuclei are stained with Hoescht blue. Merged pictures of GR and nestin on the right show double-positive NSCs. Scale bars, $30 \mu \mathrm{m}$. Control without antibody showed no staining.

embryonic NSCs express GR and MR (Fig. $1 B$ ). Immunocytochemistry for the GR showed nuclear staining in cultured NSCs after stimulation with the synthetic glucocorticoid hormone Dex (Fig. 1C). Apart from cultured NSC, developing neuroepithelium exhibited a strong reactivity for GR (Fig. 1D). Double staining of the cells showed that GR was present in cells positive for the NSC marker nestin (Fig. 1D). These results show that particularly GR receptors are present in embryonic NSCs. 

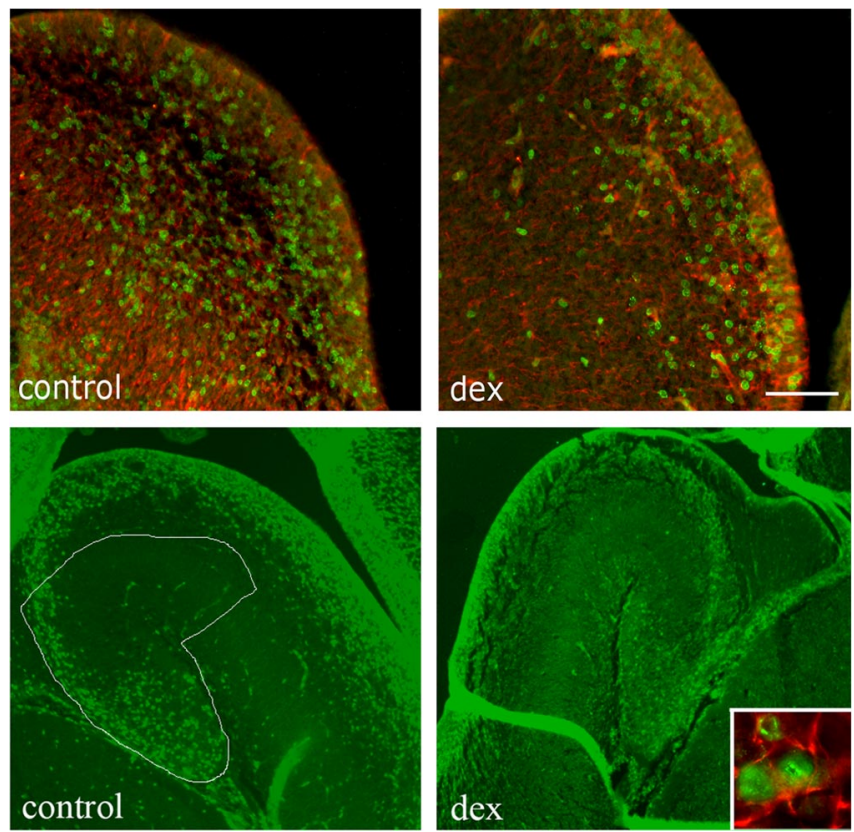

Figure 2. Effect of dexamethasone administration on BrdU labeling of NSCs in embryonic brain. Dex was injected into timed-pregnant, E14 rats in conjunction with BrdU as described in Materials and Methods. Controls received an equal volume of saline. Brains sections were prepared, stained with antibodies for BrdU (green) and nestin (red), followed by counting of cells using unbiased stereology techniques (see Materials and Methods). Top, Neuroepithelium of developing striatum reveals double-labeled cells. Bottom, Hippocampal anlage is depicted in the figure. A higher magnification of a double-labeled cell is shown in the inset to the right. Scale bar, $75 \mu \mathrm{m}$.

\section{Dexamethasone decreases proliferation of NSCs in} embryonic brain

To study whether glucocorticoids influence development of NSCs in vivo, embryonic rats were treated with Dex for $3 \mathrm{~d}$, followed by labeling of dividing cells using BrdU. NSCs were identified by the marker nestin, and the number of BrdU-nestin, double-labeled cells were counted in control and hormonetreated animals using unbiased stereology techniques (see Materials and Methods). Results on the double staining of cells in developing striatum and hippocampus are shown in Figure 2. Quantification of data showed that Dex treatment decreased the number of double-positive NSCs in developing neuroepithelium from $1210.8 \pm 49 \times 10^{3}$ in controls to $752.8 \pm 31$ cells $\times 10^{3} /$ $\mathrm{mm}^{3}$ tissue in hormone-treated rats (reduction by $37.8 \pm 3.8 \%$, means $\pm \mathrm{SD} ; n=3 ; p \leq 0.003)$. In the developing hippocampal anlage, the values for double-labeled cells were $66.8 \pm 3.9 \times 10^{3}$ in controls and $41.3 \pm 2.9 \times 10^{3}$ in hormone-treated rats. This amounts to a decrease in the number of dividing cells by $\sim 37.0 \pm$ $4 \%$ (means $\pm \mathrm{SD} ; n=3 ; p \leq 0.003$ ). This demonstrates that Dex reduces the proliferation of embryonic NSCs in vivo, which can have profound effects on brain development.

\section{Effects of glucocorticoids on the viability of embryonic NSCs in culture}

To study the role of glucocorticoids in more detail, embryonic NSCs were cultured as neurospheres in the presence of different concentrations of Dex or Cort. Figure $3 A$ shows that $1 \mu \mathrm{M}$ Dex and $1 \mu \mathrm{M}$ Cort significantly, by $\sim 40 \pm 3 \%$, reduced the viability of NSCs stimulated with EGF. To study which type of receptors are mainly involved in this effect, we used specific blockers for the GR and MR. Mifepristone, a blocker of GR receptors, inhibited the Dex-mediated decrease in cell viability and partly counter-
A

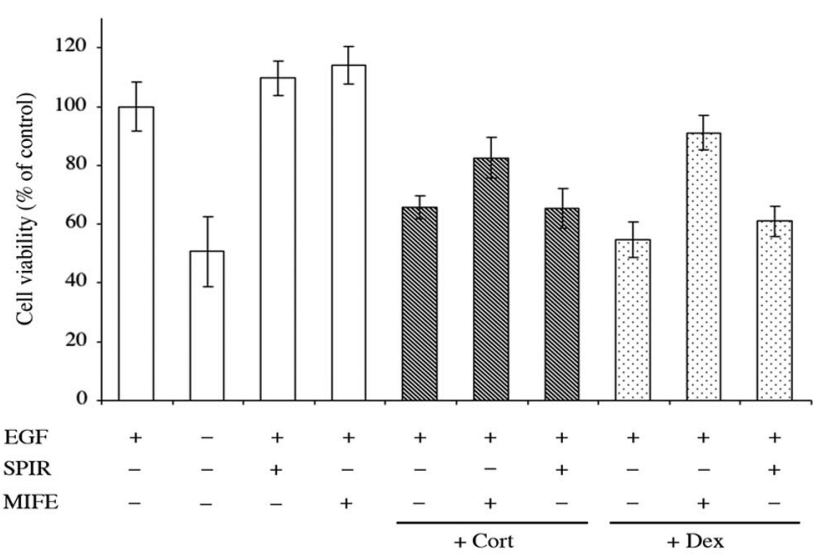

B

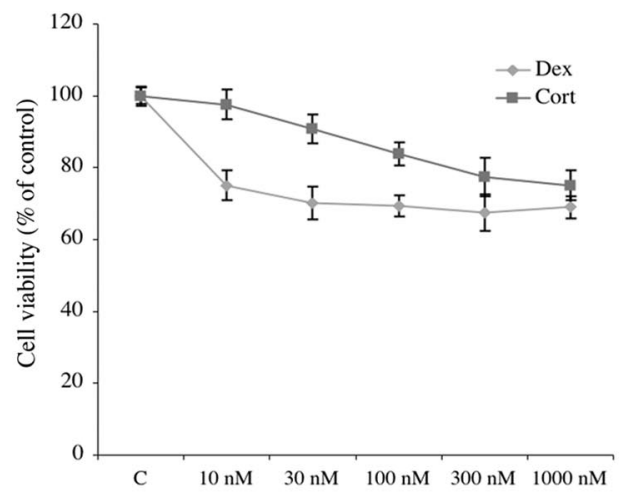

C

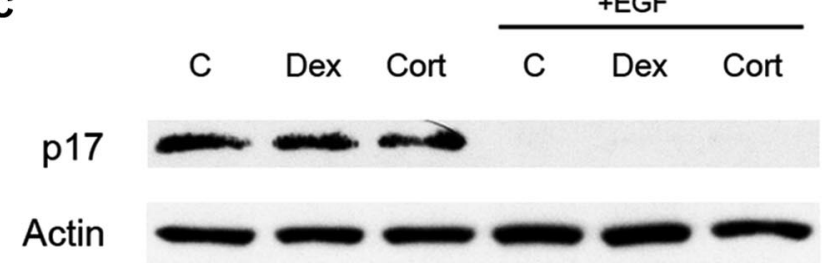

D

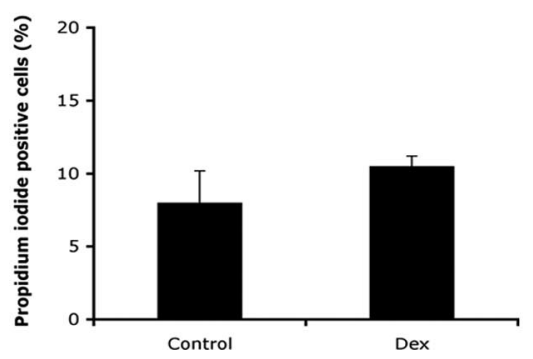

Figure 3. GR-dependent regulation of embryonic NSCs. NSC were prepared from E17 rat brain and cultured with $20 \mathrm{ng} / \mathrm{ml}$ EGF in the absence or presence of various concentration of dexamethasone (Dex) or corticosterone (Cort). Cell viability was measured by the MTT assay. Values represent mean $\pm \operatorname{SEM}(n=9)$. A, NSCs were incubated for $3 \mathrm{~d}$ in the presence of $1 \mu \mathrm{M}$ Dex or $1 \mu \mathrm{M}$ Cort. Mifepristone (MIFE) and spironolactone (SPIR) were at $2 \mu \mathrm{M} . p \leq 0.001$ for EGF versus Dex and EGF versus Cort and for Dex plus MIFE versus Dex. $p \leq 0.005$ for Cort plus MIFE versus Cort. $\boldsymbol{B}$, Dose-response curve. NSCs were incubated for 2 d. C, Control. $p \leq 0.001$ for C versus $10 \mathrm{~nm}$ and higher Dex, and C versus $30 \mathrm{~nm}$ or higher Cort. C, Cultured NSCs were lysed, and equal amounts of proteins were subject to Western blotting using an antibody against cleaved caspase-3 (17 kDa) as described in Materials and Methods. Note activation of caspase-3 in the absence of EGF but no effect of the hormone treatment. $\boldsymbol{D}$, Propidium iodine was added to the cultures to assay cell viability. Number of cells taken up this compound is shown with no difference between groups. 
acted the reduction observed with Cort (Fig. 3A). In contrast, the MR-specific blocker spironolactone had no effect on hormonetreated NSCs (Fig. 3A). Study of the dose-response curve showed that $10 \mathrm{~nm}$ Dex was able to decrease viability of the embryonic NSCs (Fig. 3B). In contrast, the effect of Cort was discernible only with $>30 \mathrm{~nm}$ of ligand (Fig. $3 B$ ). These results showed that the effect of glucocorticoids occurs through activation of GR. The saturation of the GR is thought to occur with nanomolar concentrations of ligand (de Kloet et al., 1998), suggesting that physiological concentrations of glucocorticoids can influence embryonic NSCs.

\section{Effects of glucocorticoids on the proliferation of NSCs in culture}

The decrease in the viability of embryonic NSC elicited by Dex could be attributable to reduced proliferation or increased cell death occurring in dividing cells. We observed no indications for increased cell death elicited by glucocorticoids in the NSC cultures. This is evident from the absence of caspase- 3 cleavage in hormone-treated cells (Fig. 3C), the lack of condensated nuclei with DNA fragmentation that occurs during cell death (Fig. 1C), and by the unchanged number of propidium iodine-stained cells (Fig. 3D). As a positive control for caspase activation, the withdrawal of EGF led to cleavage of caspase-3, as shown in Figure 3C. We then studied cell proliferation directly using BrdU labeling. Figure $4 A$ shows that the number of labeled embryonic NSCs was decreased after hormone treatment. Quantification of the data revealed that Dex decreased BrdU labeling by $\sim 60 \%$ from $65 \pm$ $4 \%$ in controls to $26 \pm 5 \%$ positive cells in treated cultures (Fig. $4 B)$. The corresponding value in Cort-treated cultures was $38 \pm$ $4 \%$ of BrdU-labeled cells, showing a $40 \%$ inhibition (Fig. 4 B). Treatment of NSC with mifepristone abolished the decrease in cell proliferation elicited by Dex, showing an involvement of GR (Fig. 3C). Because neurospheres are heterogeneous clusters of cells, we studied whether the hormone directly affected NSCs positive for the marker nestin. The results showed that the number of nestin-positive NSCs decreased by 40 and 30\% in Dexand Cort-stimulated cells (Fig. 3D). The results in Figure 4 on cultured embryonic NSCs are in close line with the data observed in vivo using Dex (Fig. 2). These findings show that the decrease in the viability of NSCs by glucocorticoids results from an effect on cell proliferation. To study possible effects of glucocorticoids on cell differentiation, we incubated the embryonic NSCs with hormone and stained for cell-specific markers for neurons and glia cells. The results in Figure 5 show that $1 \mu \mathrm{M}$ Dex and Cort did not influence cell differentiation of embryonic NSCs.

\section{Activation of GR decreases cyclin D1 levels in embryonic NSCs}

To study the mechanisms by which glucocorticoids affect NSC proliferation, we first analyzed whether Dex has an effect on the levels of EGF receptors in the embryonic NSCs but found no decrease in EGF receptors in hormone-stimulated cells (data not shown). We then studied levels of cell cycle regulators in the NSCs using Western blotting. Figure $6 \mathrm{~A}$ shows that Dex did not influence the levels of the cyclin dependent kinase (CDK) inhibitors p18, p27, and p57 that affect the cell cycle (Sherr and Roberts, 1995). In contrast, the levels of cyclin D1 were dramatically reduced in embryonic NSCs in the presence of Dex and to a lesser degree with Cort (Fig. 6B). The effect was observed in EGFstimulated and -deprived cells (Fig. 6B). Study of the time course showed that the decrease in cyclin D1 by Dex was observed after $6 \mathrm{~h}$ stimulation, with a maximum attained at $12 \mathrm{~h}$ (Fig. $6 \mathrm{C}$ ). The
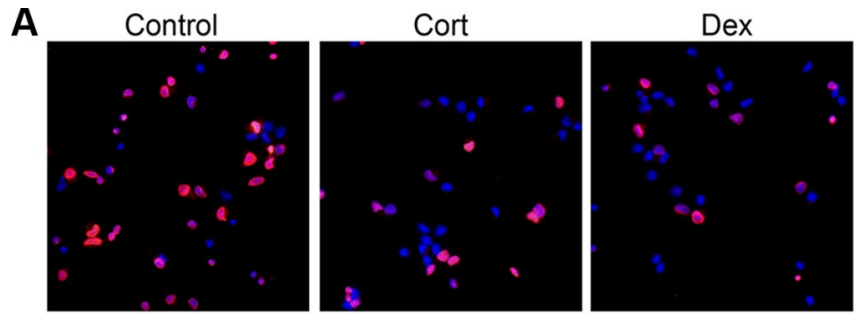

B

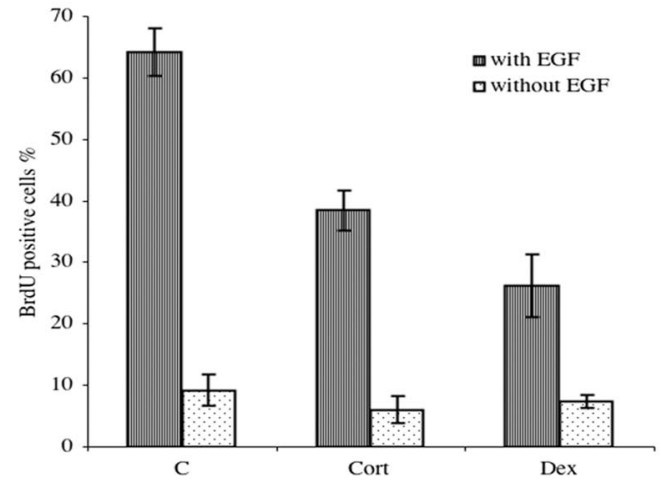

C

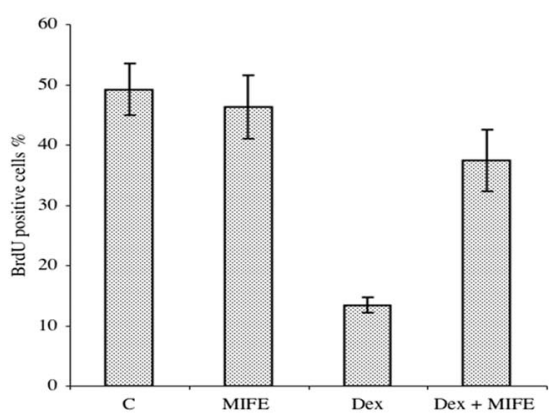

D

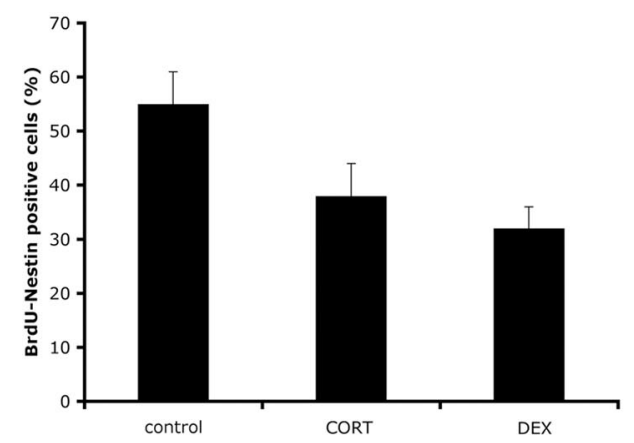

Figure 4. Effect of glucocorticoids on the proliferation of embryonic NSCs. Embryonic NSCs were cultured for $3 \mathrm{~d}$ in the absence or presence of $20 \mathrm{ng} / \mathrm{ml}$ EGF in conjunction with $1 \mu \mathrm{m}$ Dex or $1 \mu \mathrm{m}$ Cort. Cell proliferation was measured using BrdU labeling as described in Materials and Methods. Values represent mean \pm SEM $(n=9)$. $A$, Labeling of cells with BrdU (red). Nuclei were visualized by Hoescht blue. Note a decrease in labeling with the hormones. B, Quantification of data. $C$, Control. $p \leq 0.001$ for $C$ versus Dex and for C versus Cort. C, Effect of $2 \mu \mathrm{m}$ mifepristone (MIFE). C, Control. $p \leq 0.001$ for C versus Dex and for Dex plus MIFE versus Dex. D, Cells were double stained using antibodies against BrdU and nestin as described in Materials and Methods. Note a decrease in the labeling of nestin-positive NSCs by the hormones.

activation of GR was crucial for the effect, because mifepristone inhibited the decrease in cyclin D1 observed with Dex (Fig. 7A), To study whether the effect involves RNA or protein syntheses, NSCs were treated with Dex in the presence of actinomycin D and cycloheximide, respectively. The results on actinomycin D showed that this blocker did not alleviate the hormone-dependent decrease in cyclin D1, but the inhibitor itself reduced cyclin D1 in the NSCs (Fig. 7B). A similar finding was observed with cycloheximide (data 


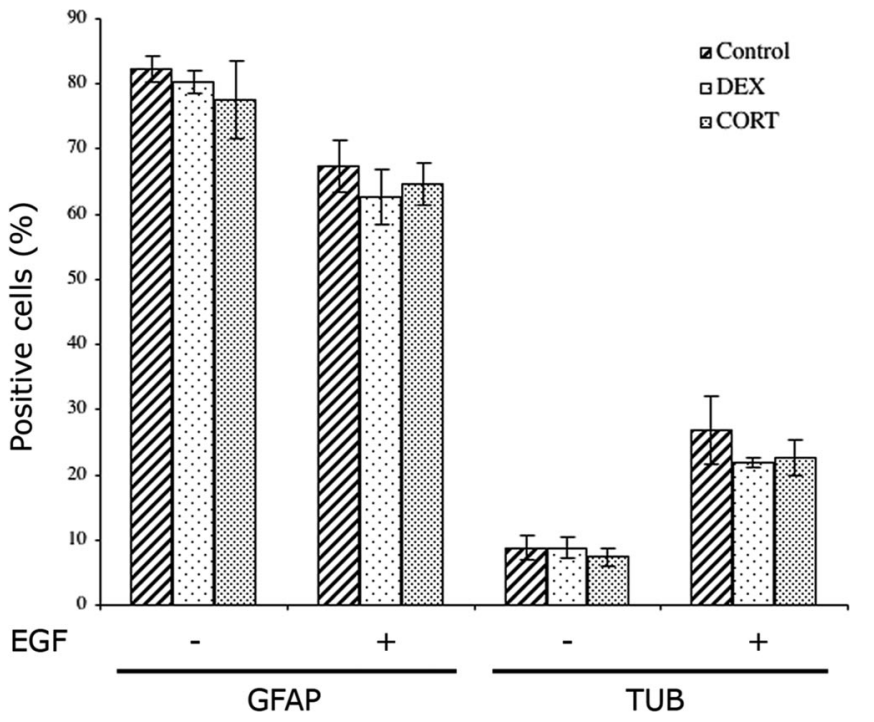

Figure 5. Effects of glucocorticoids on cell differentiation. Embryonic NSCs were incubated for $5 \mathrm{~d}$ in the absence or presence of $1 \mu \mathrm{m}$ Dex or $1 \mu \mathrm{m}$ Cort. Cells were fixed and immunostained with antibodies against glial fibrillary acidic protein (GFAP) and $\beta$-tubulin (TUB) as described in Materials and Methods. There was no change in the relative proportion of glia and neuronal cells by the hormones.

not shown). This indicates that cyclin D1 is constantly turned over in the NSCs, which depends on ongoing RNA and protein syntheses. In addition, RT-PCR revealed no change in mRNA levels for cyclin D1 after treatment with Dex, indicating a posttranscriptional effect of the hormone (Fig. 6E).

\section{Involvement of proteasome activity in dexamethasone- induced decrease of cyclin D1}

External stimuli and various signaling cascades, such as the glycogen synthase kinase- $\beta$ (GSK $\beta$ ) pathway, are known to affect cyclin D1 (Diehl et al., 1998). To study whether the GSK $\beta$ pathway is involved in the Dex-mediated effect, we incubated NSCs in the presence of $\mathrm{LiCl}$, inhibiting GSK $\beta$. Figure $7 C$ shows that treatment with $\mathrm{LiCl}$ elevated cyclin D1 in the NSCs, which was particularly strong at $16 \mathrm{~h}$ of treatment. However, the downregulation of cyclin D1 caused by Dex was not blocked by $\mathrm{LiCl}$, as shown here for the $24 \mathrm{~h}$ incubation (Fig. 7C). A similar finding was made using the specific GSK $\beta$ inhibitor AR-A014418 [ $N$-(4-methoxybenzyl)- $N^{\prime}$-(5-nitro-1,3-thiazol-2-yl)urea] (data not shown). This shows that, although GSK $\beta$ is active in the NSCs, Dex acts via other mechanisms not directly related to this pathway. To explore this further, MG132 (benzyloxycarbonyl-leucyl-leucyl-leucinal) was used to inhibit the ubiquitin proteasome system (UPS) in the embryonic NSCs. The results demonstrated that blocking of proteasome activity by MG132 counteracted the degradation of cyclin D1 induced by Dex (Fig. $8 \mathrm{~A}$ ). A similar finding was observed also using lactacystin to block the proteasome (Fig. $8 A$ ). These data demonstrate that the activation of GR by Dex results in the decline of cyclin D1 via the UPS, which determines the degradation of this protein in the embryonic NSCs. To study the underlying mechanisms, the degree of ubiquitination of cyclin D1 was examined using immunoprecipitation, followed by Western blot with anti-ubiquitin antibodies. MG132 as a control increased the amount of ubiquitinated cyclin D1 in the NSCs (Fig. 8C), as did the addition of Dex (Fig. 8C). Control experiments using anti-GFP antibodies for immunoprecipitation did not reveal any cyclin D1 or protein ubiquitination (Fig. $8 B, C$ ). Moreover, the total levels of ubiquitinated protein spe-
A

p18

Actin

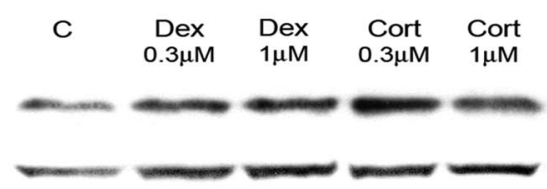

B

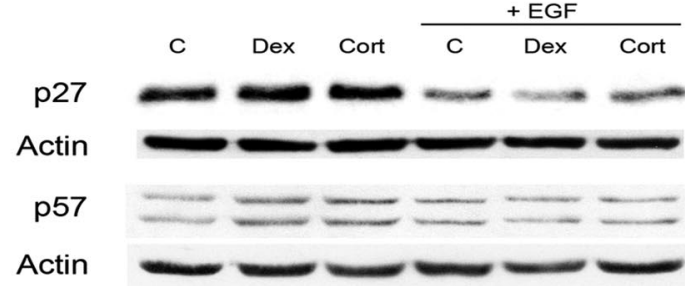

C
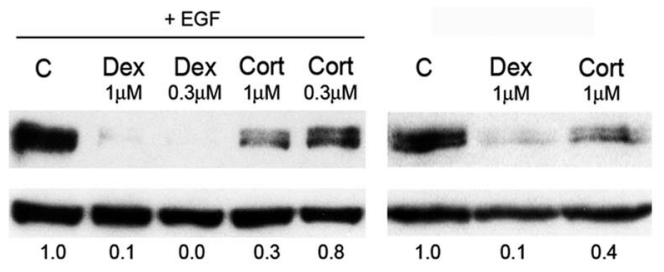

D

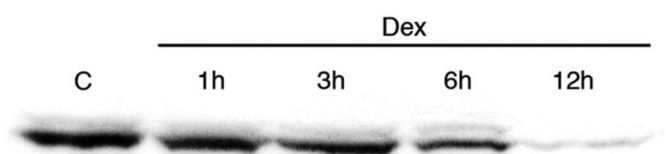

Cyclin D1

Actin

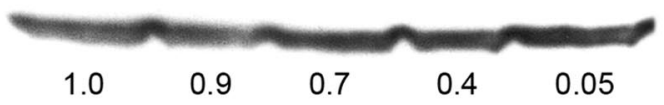

E

Cyclin D1

C Dex

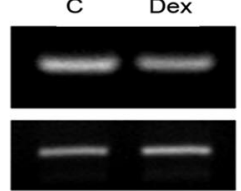

Figure 6. Effects of glucocorticoids on cell cycle regulators. Embryonic NSCs were cultured for $24 \mathrm{~h}$ in the absence or presence of different concentrations of Dex or Cort. Cells were lysed and equal amounts of proteins were subject to Western blotting as described in Materials and Methods. Specific antibodies for the different proteins were used, and $\beta$-actin was control. $\boldsymbol{A}, \boldsymbol{B}$, p18, p27, and p57. No differences were observed in expression levels for control (C) versus Dex or Cort. C, Cyclin D1 in the presence or absence of $20 \mathrm{ng} / \mathrm{ml}$ EGF. Values below are relative expression levels quantified by Gel Doc analyses (Bio-Rad, Hercules, CA). D, Time course in the presence of $1 \mu \mathrm{m}$ Dex. Relative expression levels are given below. $\boldsymbol{E}$, mRNA levels for cyclin D1 were studies by using PCR as described in Materials and Methods. Note no change in cyclin D1 mRNA by Dex.

cies did not change significantly by Dex, indicating that the effect on cyclin D1 is specific (Fig. 8D). This shows that Dex enhances the ubiquitination of cyclin D1 in embryonic NSCs, leading to an inhibition of cell proliferation. To substantiate this, we incubated NSCs with Dex in the absence or presence of MG132 to study cell proliferation. Data showed that the decrease in NSC proliferation induced by Dex was reversed by MG132, blocking the proteasomal degradation of cyclin D1 (Fig. 9A). MG132 did not further increase BrdU labeling, which can be attributable to the fact that the compound may have some additional effects on the cell cycle proteins in NSCs. We also observed that overexpression of cyclin D1 in the NSCs increased cell proliferation and counteracted the effect observed with Dex (Fig. 9B). This demonstrates that the levels of cyclin D1 control the proliferation of embryonic NSCs and that Dex can inhibit this process through the UPS via the degradation cyclin D1. 


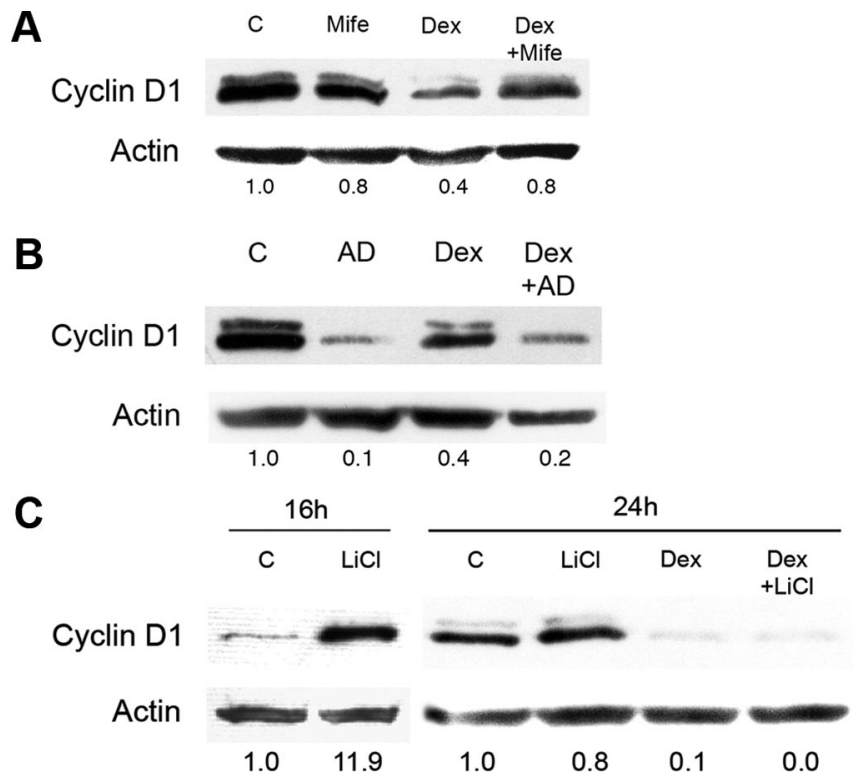

Figure 7. Effect of various inhibitors on the glucocorticoid-dependent regulation of cyclin D1. Embryonic NSCs were cultured for 16 or $24 \mathrm{~h}$ in the absence or presence of $1 \mu \mathrm{m}$ Dex. Inhibitors were added together with the hormones as indicated. Western blots were performed and cyclin D1 levels were quantified as described in Materials and Methods. Relative expression levels are given below. $\boldsymbol{A}$, Effect of $2 \mu \mathrm{m}$ mifepristone (Mife). Incubation was for $24 \mathrm{~h}$. $\boldsymbol{B}$, Effect of $10 \mu \mathrm{m}$ actinomycin $D(A D)$, inhibiting gene transcription. Incubation was for $16 \mathrm{~h}$. C, Effect of $3 \mathrm{~mm} \mathrm{LiCl,} \mathrm{inhibiting} \mathrm{GSK} \beta 3$. Incubation times as indicated. C, Control.

\section{Discussion}

The results in the present study demonstrate that glucocorticoid hormones influence proliferation of embryonic NSCs by activating the cognate GRs. The mechanism was shown to involve ubiquitination of cyclin D1 and the degradation of the protein by the UPS. Cyclin D1 is rapidly turned over in the NSCs, and the levels are regulated by the activity of GSK $\beta$, as shown previously in other cells (Diehl et al., 1998). Our data showed that inhibition of GSK $\beta$ increased cyclin D1 levels in control, but not in Dex-treated, NSCs. This suggested another pathway for Dex in the regulation of cyclin D1 in these cells. We observed that the addition of Dex increased the ubiquitination of cyclin D1, which is a prerequisite for its degradation via the UPS. Inhibition of UPS by MG132 restored the levels of cyclin D1 and counteracted the decrease in cell proliferation caused by Dex. This demonstrates that Dex regulates proliferation of NSCs through action on cyclin D1. Cyclin D1 has been shown previously to undergo ubiquitination via the activity of the SKP1/SKP2/ CUL-1 E3 ligase complex (Yu et al., 1998). The exact mechanisms by which Dex induces ubiquitination of cyclin D1 in the NSCs and the role of specific E3 ligases in this process remain to be studied in the future.

The crucial roles of type D cyclins in the regulation of NSCs was reported recently for adult NSCs in which lack of cyclin D2 inhibited cell cycle and neurogenesis (Kowalczyk et al., 2004). The present findings show that activation of GR can profoundly decrease cyclin D1 levels, leading to inhibition of cell proliferation in embryonic NSCs. In preliminary experiments, we observed low levels of cyclin D2 in the embryonic NSCs, which were not further decreased by Dex (data not shown). This suggests that cyclin D1 is important for the regulation of NSCs proliferation during embryonic life, whereas cyclin D2 is more crucial in the adult brain (Kowalczyk et al., 2004). Three type D cyclins have been cloned in mammals (Kozar et al., 2004). As shown by studies in gene-deleted mice, the roles of the different type D cyclins in
A

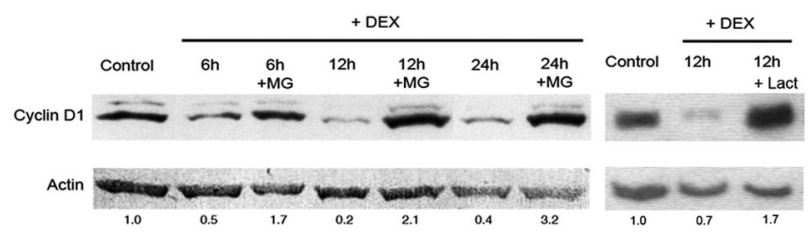

B

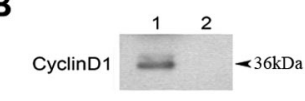

C

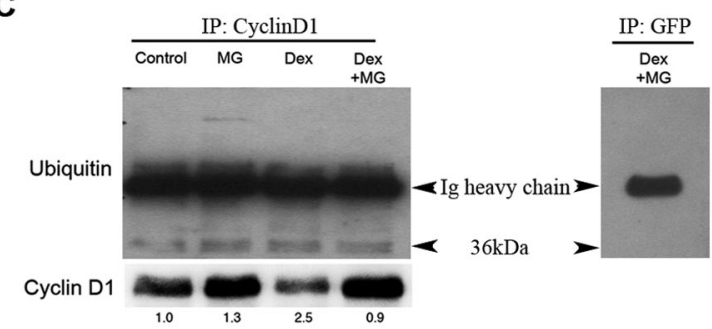

D

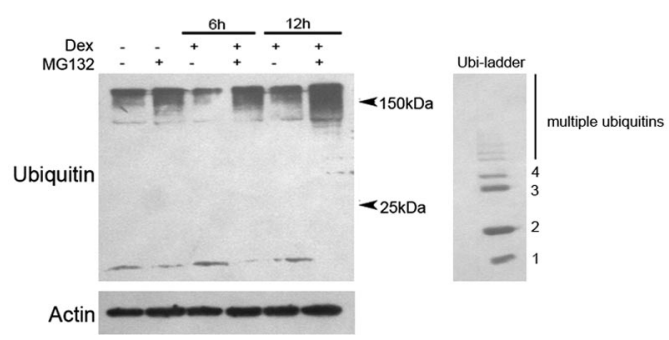

Figure 8. Role of the UPS in the degradation of cyclin D1 by glucocorticoids in NSCs. $\boldsymbol{A}$, Embryonic NSCs were cultured for various time periods with $1 \mu \mathrm{m}$ Dex in the absence or presence of $10 \mu \mathrm{MMG} 132(\mathrm{MG})$ to inhibit the proteasome. Western blots were performed and cyclin D1 levels were quantified as described in Materials and Methods. Relative expression levels are given below. Note restored cyclin D1 levels in the presence of MG132. Right shows experiments with the proteasome inhibitor lactacystin, giving similar results. B, Cyclin D1 was immunoprecipitated from NSCs by the cyclin D1 antibody (lane 1) but not by the irrelevant GFP antibody (lane 2). C, Cyclin D1 was immunoprecipitated (IP) from NSCs treated with $1 \mu \mathrm{m}$ Dex or $10 \mu \mathrm{M}$ MG or both. Western blots were performed and the degree of cyclin D1 ubiquitination was determined using the anti-ubiquitin antibody. Arrowheads show the presence of ubiquitinated cyclin D1 at $36 \mathrm{kDa}$, and the upper band is the Ig heavy chain. Right shows control experiment using the GFP antibody for immunoprecipitation and anti-ubiquitin antibodies for blotting. Note an increase in ubiquitination of cyclin D1 after Dex. Bottom shows total cyclin D1 levels in the immunoprecipitate. Values below are the ratios of ubiquitinated to total cyclin D1. D, Total levels of ubiquitination in NSC. Western blotting was performed using the ubiquitin antibody that recognizes both mono-ubiquitin and poly-ubiquitin. The ladder to the right shows the localization of mono-ubiquitinated and poly-ubiquitinated species. Data indicates no general effect by Dex on the levels of mono-ubiquitin or poly-ubiquitin species in NSCS.

the control of cell cycle vary between tissues and cells (Kozar et al., 2004). Mice lacking cyclin D1 show developmental neurological abnormalities and hypoplastic retinas, whereas cyclin D2deficient animals have cerebellar defects (Fantl et al., 1995; Huard et al., 1999). In animals lacking all D-type cyclins, the proliferation of hematopoietic stem cells is severely affected during embryonic life. Because of prenatal lethality, the nervous system of these animals has so far not been analyzed. In the future, it is important to study whether glucocorticoids can influence the development of other stem cell populations than NSCs and whether this occurs through regulation of cyclin $\mathrm{D}$ proteins.

In this context, it is interesting to note that the relative decrease in cyclin D1 by Dex was greater than the degree of inhibition of cell proliferation (compare Figs. 2B, 6C). The reason for this is not clear at the moment, but it is known from studies of fibroblasts lacking cyclin D that cell cycle progression can be driven 
A
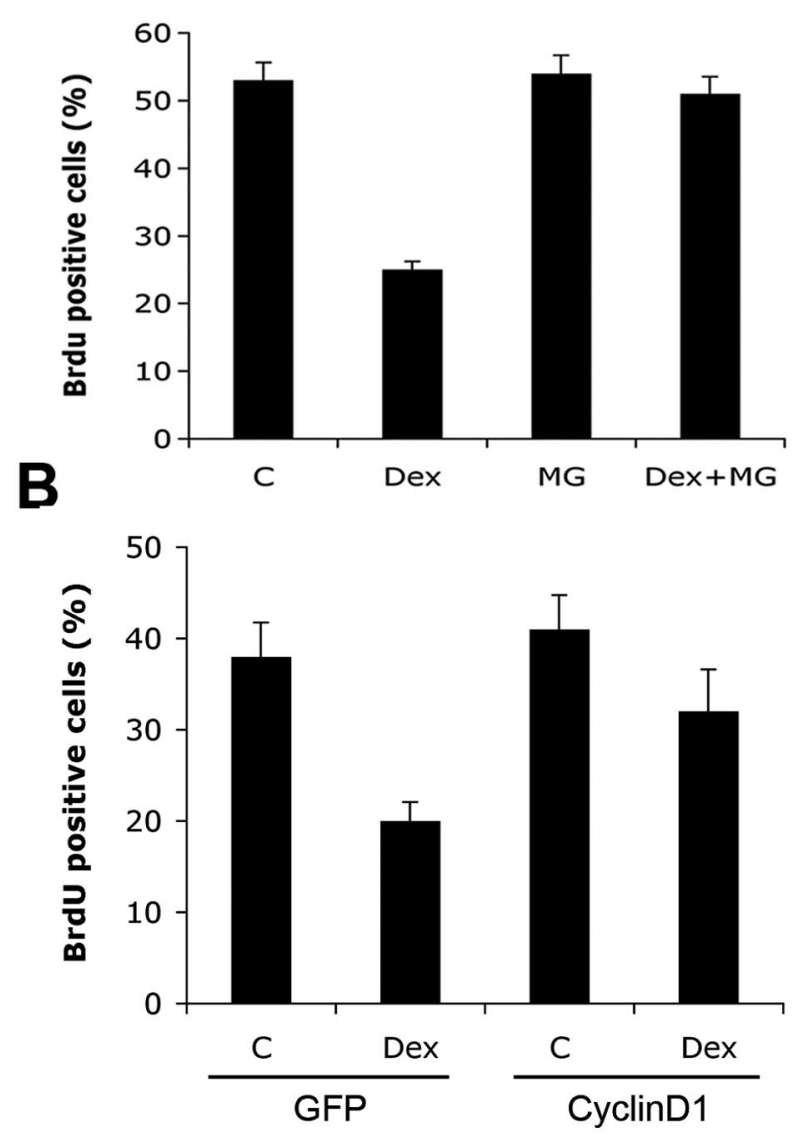

C

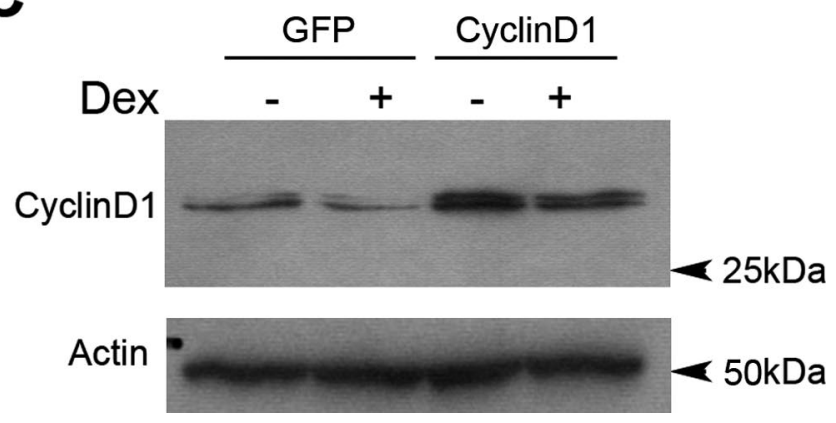

Figure 9. Role of cyclin D1 in the proliferation of NSCs. A, Reversal of Dex-mediated inhibition by MG132 (MG). Embryonic NSCs were incubated for $3 \mathrm{~d}$ with $1 \mu \mathrm{M}$ Dex in the absence or presence of $0.5 \mu \mathrm{M}$ MG. Cell proliferation was measured using BrdU labeling as described in Materials and Methods. Values represent mean \pm SEM $(n=4)$. Note the reversal of Dexmediated inhibition by MG. $\boldsymbol{B}$, Effect of cyclin D1 overexpression. NSC were transfected with expression vectors encoding cyclin D1 or GFP as control. Cell proliferation was measured using BrdU labeling and values represent mean $\pm \operatorname{SEM}(n=3)$. Note the increase in cell proliferation in cells transfected with cyclin D1 and treated with Dex. C, Western blots for cyclin D1. Note the increase in cyclin D1 in transfected cells. C, Control.

by other proteins in the CDK2 complex (Kozar et al., 2004). Whether this is also the case for embryonic NSCs remains to be studied.

In our study, the addition of Dex and Cort inhibited the proliferation of cultured NSC by activation of GR expressed by these cells. Mifepristone, a blocker of the GR, inhibited the effect, whereas spironolactone, acting on MR did not. These data are consistent with the relative high expression of GR in the NSCs in both culture and the developing neuroepithelium. Compared with GR, MR has a more restricted expression in the brain and is found mainly in the adult rat hippocampus (de Kloet et al., 1998, 2005). Study of the dose-response curve showed that $10 \mathrm{~nm}$ Dex was able to reduce proliferation of embryonic NSCs. The concentration of corticosteroids to half saturate the cognate receptors is thought to be $\sim 10 \mathrm{~nm}$ (de Kloet et al., 1998). This suggests that the observed effects of glucocorticoids on embryonic NSCs may also occur in vivo under certain conditions. The physiological concentrations of glucocorticoids in brain tissue especially during development are, however, hard to predict. The present results indicate that, in situations with higher concentrations of glucocorticoids exemplified by prenatal-induced stress, the hormones may attain high enough levels to influence the development of the NSCs. To study this in more detail, we injected Dex to embryonic rats followed by analyses of BrdU-labeled NSCs. In keeping with data in vitro, Dex administration in vivo reduced cell proliferation of NSCs by approximately one-third. The effect was observed in embryonic NSCs within developing striatal neuroepithelium and in the developing hippocampal anlage. These data demonstrate that glucocorticoid hormones can decrease proliferation of NSCs in embryonic brain and profoundly affect brain development.

Apart from cell proliferation, glucocorticoids may possibly influence cell death or differentiation of embryonic NSCs. The results obtained showed that there was no difference between control and treated NSCs with regard to cell death markers and the activation of caspase-3. This suggests that enhanced caspase activation and cell death play minor roles in the decrease in NSC number mediated by Dex.

In addition, we were unable to detect any influence of glucocorticoids on differentiation of NSCs. Thus, there was no significant change in the relative proportion of developing neurons and glia cells in NSCs after treatment with Dex. These data are in contrast with our previous studies on sex steroids, showing a relatively higher proportion of $\beta$-tubulin-positive neurons in embryonic NSCs treated with either estrogen or androgens (Brännvall et al., 2002, 2005). To compare the physiological roles of corticosteroids and sex steroids in embryonic NSCs in more detail, we performed initial studies on the addition of Dex together with either estrogen or androgen. However, because of the dramatic decrease in the proliferation of embryonic NSCs by Dex, the studies on cell differentiation became hard to pursue. In this context, the future analyses of the hormone interactions in NSCs may be more rewarding to perform in vivo.

In brain, GRs are expressed by different regions and by both neurons and glial cells (Lindholm et al., 1992; de Kloet et al., 1998). The ontogeny of the GR has been studied in rodent and recently also in marmoset monkey brain tissue (Van Eekelen et al., 1991; Schmidt et al., 2003; Pryce et al., 2005). Previous studies on rat hippocampus showed that prenatal stress reduced neurogenesis and caused an impairment of hippocampal-dependent spatial learning as observed later in life (Lemaire et al., 2000). A part of this stress effect was ascribed to an increased activity of the HPA axis with higher levels of glucocorticoids. The stressmediated effect on neurogenesis was suggested to be indirect, occurring primarily through effects on the activity of the serotonergic system by glucocorticoids (Lemaire et al., 2000).

We show here that GRs are abundantly present in embryonic NSCs, and their activation by Dex dramatically reduces the proliferation of NSCs, as shown in vivo and in vitro. The present results suggest that the higher levels of glucocorticoid hormones, which may occur after prenatal stress, can directly inhibit the prolif- 
eration of NSCs. The present data also show that embryonic NSCs are important targets for the action of glucocorticoids in developing brain. The physiological and long-term consequences of the glucocorticoid-mediated regulation of the proliferation and number of developing NSCs warrant additional studies.

\section{References}

Åberg MA, Åberg ND, Hedbacker H, Oscarsson J, Eriksson PS (2000) Peripheral infusion of IGF-I selectively induces neurogenesis in the adult rat hippocampus. J Neurosci 20:2896-2903.

Beato M (1989) Gene regulation by steroid hormones. Cell 56:335-344.

Brännvall K, Korhonen L, Lindholm D (2002) Estrogen-receptordependent regulation of neural stem cell proliferation and differentiation. Mol Cell Neurosci 21:512-520.

Brännvall K, Bogdanovic N, Korhonen L, Lindholm D (2005) 19Nortestosterone influences neural stem cell proliferation and neurogenesis in the rat brain. Eur J Neurosci 21:871-878.

Cameron HA, Gould E (1994) Adult neurogenesis is regulated by adrenal steroids in the dentate gyrus. Neuroscience 61:203-209.

Crochemore C, Lu J, Wu Y, Liposits Z, Sousa N, Holsboer F, Almeida OF (2005) Direct targeting of hippocampal neurons for apoptosis by glucocorticoids is reversible by mineralocorticoid receptor activation. Mol Psychiatry 10:790-798.

de Kloet ER, Vreugdenhil E, Oitzl MS, Joels M (1998) Brain corticosteroid receptor balance in health and disease. Endocr Rev 19:269-301.

de Kloet ER, Joels M, Holsboer F (2005) Stress and the brain: from adaptation to disease. Nat Rev Neurosci 6:463-475.

Diehl JA, Cheng M, Roussel MF, Sherr CJ (1998) Glycogen synthase kinase3beta regulates cyclin D1 proteolysis and subcellular localization. Genes Dev 12:3499-3511.

Fantl V, Stamp G, Andrews A, Rosewell I, Dickson C (1995) Mice lacking cyclin D1 are small and show defects in eye and mammary gland development. Genes Dev 9:2364-2372.

Fuxe K, Wikstrom AC, Okret S, Agnati LF, Harfstrand A, Yu ZY, Granholm L, Zoli M, Vale W, Gustafsson JA (1985) Mapping of glucocorticoid receptor immunoreactive neurons in the rat tel-diencephalon using a monoclonal antibody against rat liver glucocorticoid receptor. Endocrinology 117:1803-1812.

Gass P, Reichardt HM, Strekalova T, Henn F, Tronche F (2001) Mice with targeted mutations of glucocorticoid and mineralocorticoid receptors: models for depression and anxiety? Physiol Behav 73:811-825.

Gould E, Gross CG (2002) Neurogenesis in adult mammals: some progress and problems. J Neurosci 22:619-623.

Gould E, Tanapat P, McEwen BS, Flugge G, Fuchs E (1998) Proliferation of granule cell precursors in the dentate gyrus of adult monkeys is diminished by stress. Proc Natl Acad Sci USA 95:3168-3171.

Hienola A, Pekkanen M, Raulo E, Vanttola P, Rauvala H (2004) HB-GAM inhibits proliferation and enhances differentiation of neural stem cells. Mol Cell Neurosci 26:75-88.

Huard J, Forster C, Carter M, Sicinski P, Ross M (1999) Cerebellar histogenesis is disturbed in mice lacking cyclin D2. Development 126:1927-1935.

Karishma KK, Herbert J (2002) DHEA stimulates neurogenesis in the hippocampus of the rat, promotes survival of newly formed neurons and prevents corticosteroid-induced suppression. Eur J Neurosci 16:445-454.

Korhonen L, Belluardo N, Lindholm D (2001) Regulation of X-chromosome- linked inhibitor of apoptosis protein in kainic acid-induced neuronal death in the rat hippocampus. Mol Cell Neurosci 17:364-372.

Korhonen L, Brännvall K, Skoglösa Y, Lindholm D (2003) Tumor suppressor gene BRCA-1 is expressed by embryonic and adult neural stem cells and involved in cell proliferation. J Neurosci Res 71:769-776.

Kowalczyk A, Filipkowski RK, Rylski M, Wilczynski GM, Konopacki FA, Jaworski J, Ciemerych MA, Sicinski P, Kaczmarek L (2004) The critical role of cyclin D2 in adult neurogenesis. J Cell Biol 167:209-213.

Kozar K, Ciemerych MA, Rebel VI, Shigematsu H, Zagozdzon A, Sicinska E, Geng Y, Yu Q, Bhattacharya S, Bronson RT, Akashi K, Sicinski P (2004) Mouse development and cell proliferation in the absence of D-cyclins. Cell 118:477-491.

Lemaire V, Koehl M, Le Moal M, Abrous DN (2000) Prenatal stress produces learning deficits associated with an inhibition of neurogenesis in the hippocampus. Proc Natl Acad Sci USA 97:11032-11037.

Lindholm D, Castren E, Hengerer B, Zafra F, Berninger B, Thoenen H (1992) Differential regulation of nerve growth factor (NGF) synthesis in neurons and astrocytes by glucocorticoid hormones. Eur J Neurosci 4:404-410.

Mouton PR, Long JM, Lei DL, Howard V, Jucker M, Calhoun ME, Ingram DK (2002) Age and gender effects on microglia and astrocyte numbers in brains of mice. Brain Res 956:30-35.

Perfilieva E, Risedal A, Nyberg J, Johansson BB, Eriksson PS (2001) Gender and strain influence on neurogenesis in dentate gyrus of young rats. J Cereb Blood Flow Metab 21:211-217.

Pryce CR, Feldon J, Fuchs E, Knuesel I, Oertle T, Sengstag C, Spengler M, Weber E, Weston A, Jongen-Relo A (2005) Postnatal ontogeny of hippocampal expression of the mineralocorticoid and glucocorticoid receptors in the common marmoset monkey. Eur J Neurosci 21:1521-1535.

Schanzer A, Wachs FP, Wilhelm D, Acker T, Cooper-Kuhn C, Beck H, Winkler J, Aigner L, Plate KH, Kuhn HG (2004) Direct stimulation of adult neural stem cells in vitro and neurogenesis in vivo by vascular endothelial growth factor. Brain Pathol 14:237-248.

Schmidt M, Enthoven L, van der Mark M, Levine S, de Kloet ER, Oitzl MS (2003) The postnatal development of the hypothalamic-pituitaryadrenal axis in the mouse. Int J Dev Neurosci 21:125-132.

Sherr CJ, Roberts JM (1995) Inhibitors of mammalian G1 cyclin-dependent kinases. Genes Dev 9:1149-1163.

Tanapat P, Hastings NB, Reeves AJ, Gould E (1999) Estrogen stimulates a transient increase in the number of new neurons in the dentate gyrus of the adult female rat. J Neurosci 19:5792-5801.

Tanapat P, Hastings NB, Gould E (2005) Ovarian steroids influence cell proliferation in the dentate gyrus of the adult female rat in a dose- and time-dependent manner. J Comp Neurol 481:252-265.

Taupin P, Gage FH (2002) Adult neurogenesis and neural stem cells of the central nervous system in mammals. J Neurosci Res 69:745-749.

Van Eekelen JAM, Bohn MC, de Kloet ER (1991) Postnatal ontogeny of mineralocorticoid and glucocorticoid receptor gene expression in regions of the rat tel- and diencephalon. Dev Brain Res 61:33-43.

Yu LY, Korhonen L, Martinez R, Jokitalo E, Chen Y, Arumäe U, Lindholm D (2003) Regulation of sympathetic neuron and neuroblastoma cell death by XIAP and its association with proteasomes in neural cells. Mol Cell Neurosci 22:308-318.

Yu ZK, Gervais JL, Zhang H (1998) Human CUL-1 associates with the SKP1/SKP2 complex and regulates p21 (CIP1/WAF1) and cyclin D proteins. Proc Natl Acad Sci USA 95:11324-11329. 